\title{
Surgical Resection of Relapse May Improve Postrelapse Survival of Patients With Localized Osteosarcoma
}

\author{
Kwok Chuen Wong FHKAM (Orth), Vincent Lee FHKAM (Paed), MRCP , \\ Matthew M. K. Shing FHKAM (Paed), MRCPCH, \\ Shekhar Kumta PhD
}

Published online: 13 September 2012

(C) The Association of Bone and Joint Surgeons (B) 2012

\begin{abstract}
Background Despite neoadjuvant chemotherapy and wide surgical ablation, $15 \%$ to $25 \%$ of patients with primary osteosarcoma will relapse (local recurrence or metastases). Neither chemotherapy nor radiation therapy alone will render a patient disease-free without concomitant surgical ablation of relapse. We prefer excision of relapse when possible. However, it is unclear whether excision enhances survival.

Questions/purposes We therefore determined (1) onset, location, and treatments for relapse; (2) postrelapse diseasefree survival of patients who underwent surgical ablation and those who did not; and (3) relapse-free interval between initial diagnosis and first relapse in survivors and in those who died of their disease.
\end{abstract}

Each author certifies that he or she, or a member of their immediate family, has no commercial associations (eg, consultancies, stock ownership, equity interest, patent/licensing arrangements, etc) that might pose a conflict of interest in connection with the submitted article.

All ICMJE Conflict of Interest Forms for authors and Clinical Orthopaedics and Related Research editors and board members are on file with the publication and can be viewed on request.

Each author certifies that his or her institution approved the human protocol for this investigation, that all investigations were conducted in conformity with ethical principles of research, and that informed consent for participation in the study was obtained.

K. C. Wong, S. Kumta ( $\square)$

Department of Orthopaedics and Traumatology,

Prince of Wales Hospital, The Chinese University

of Hong Kong, Shatin NT, Hong Kong SAR, China

e-mail: kumta@cuhk.edu.hk

V. Lee M. M. K. Shing

Department of Paediatrics, Prince of Wales Hospital,

The Chinese University of Hong Kong, Shatin NT,

Hong Kong SAR, China
Methods We retrospectively reviewed 15 children who initially presented with localized, nonmetastatic extremity osteosarcoma and attained initial complete remission after neoadjuvant chemotherapy, wide local resection, postoperative chemotherapy, and subsequently developed disease relapse. Relapse occurred at a median of 28 months, although late relapse after 5 years occurred in three. We resected the recurrent tumor in nine patients and treated six nonoperatively.

Results Seven of nine surgically treated patients had a postrelapse disease-free survival ranging from 3 to 14 years and an overall survival ranging from 7 to 16 years. Patients not surgically treated all died within 40 months of their relapse. The median relapse-free interval in patients who survived was longer 34 months (range, 17-152 months) as compared with 17 months (range, 7-40 months) in those who died of their disease.

Conclusions Our data confirm the importance of surgery in patients with relapsed osteosarcoma. Disease-free survival in patients with relapsed osteosarcoma is only possible if complete remission is attained. Patients with late relapse may have a better chance of survival.

Level of Evidence Level IV, therapeutic study. See Guidelines for Authors for a complete description of levels of evidence.

\section{Introduction}

The primary role of chemotherapy and proper surgical technique in achieving long-term survival in patients with nonmetastatic high-grade osteosarcoma remains undisputed [9]. Approximately $75 \%$ to $85 \%$ of patients will attain complete remission and cure [7], yet the others will relapse, mostly with pulmonary metastases or less frequently 
metastases to other bones. A biphasic pattern of disease failure (early and late) has been observed in posttreatment survivors of osteosarcoma with poor postrelapse survival [5]. The relapse of disease despite chemotherapy and surgical excision is a major setback for patients. The prognosis for patients with relapse remains poor with a median postrelapse survival of 14 months reported from one large cohort study of 235 patients [1]. A few studies report that survival after relapse is possible only if the relapse is completely resected. In the Cooperative Osteosarcoma Study Group (COSS) [2], 39\% of patients who underwent successful surgical ablation of relapse disease were alive at 5 years, whereas none of the patients in whom surgical clearance of relapse was not performed remained alive. Survival was also possible in $32 \%$ to $58 \%$ of those patients who subsequently developed second and subsequent relapses provided surgical clearance was performed [3]. Other studies have suggested that complete surgical clearance of relapse may enable $30 \%$ to $39 \%$ of relapsed patients to survive 7 to 10 years $[1,5]$. Studies also suggest that relapse within 24 months of initial diagnosis is associated with a poor prognosis. Although recommendations for adjuvant chemotherapy or radiation remain uncertain, one study [2] suggests surgical ablation of relapsed disease and a late onset of relapse are associated with better survival. However, this notion requires confirmation.

We therefore report (1) the onset, location, and treatments carried out for relapse; (2) the postrelapse disease-free survival of patients who underwent surgical ablation of their relapse and those who did not; and (3) the relapse-free interval between initial diagnosis and first relapse in survivors and in those who died of their disease.

\section{Patients and Methods}

Between 1994 and 2009, we treated 52 children aged 3 to 18 years (median, 13 years) who presented with localized (nonmetastatic) extremity osteosarcoma with neoadjuvant chemotherapy surgery and postoperative chemotherapy. All patients had a biopsy-proven high-grade osteosarcoma and underwent a comprehensive pretreatment evaluation of their disease, which included plain radiography of the extremity and the chest, MRI of the affected extremity, a pulmonary CT examination, a Tc-99 MDP bone scan, and biochemical and hematological investigations. Fifteen of the 52 patients (29\% of all patients with localized osteosarcoma) developed disease relapse (Table 1). There were 11 males and four females in this group with a mean age of 11 years (range, 6-17 years). The primary lesion involved the proximal tibia in six, the distal femur in four, and the proximal humerus in four patients. All patients had received neoadjuvant chemotherapy and had completed a postoperative course as per the Hong Kong Pediatric Sarcoma Group protocol. Limb salvage surgery was performed in 13 patients, all with wide margins; two patients underwent amputations and their margins were wide in one and radical in another. The minimum followup in this group of patients was 8 months (median, 86 months; range, $8-180$ months). No patients were lost to followup. No patients were recalled specifically for this study; all data were obtained from medical records.

All 15 patients received two cycles of preoperative neoadjuvant chemotherapy based on a standard protocol, which included high-dose methotrexate, Adriamycin, and cisplatin. Before surgery, pulmonary CT examination was obtained to reassess metastatic status and an MRI of the extremity was obtained to assess feasibility of achieving surgical resection and limb salvage.

All 15 patients had either wide local resection or amputation; the margin status was confirmed on histological analysis of the resected tumor. Briefly, a radiograph of the resected specimen was taken and a band saw used to split the specimen along its length. The tissues were inked and the entire specimen was divided into 12 to 16 blocks and then cut using a band saw. Each block was labeled and further sectioned into eight to 12 smaller blocks, from each of which 10 random sections were mounted on paraffin slides and selected for histological staining with hematoxylin and eosin to determine margins. The marrow, sections of the soft tissues, periarticular ligaments, and the biopsy tract were also examined for adequacy of margin. Chemonecrosis was assessed using the grading system of Huvos et al. [6]. More than $90 \%$ necrosis on the histological sections was considered a good response to chemotherapy. Of the 15 relapsed patients, five had a good response to chemotherapy, whereas 10 had a poor response. The postoperative chemotherapy protocol was initiated within 2 weeks after surgery in all study patients.

All patients were followed at a single multidisciplinary clinic in a single institution. After completion of chemotherapy, all patients were followed up every 6 weeks for the first 2 years, every 2 to 4 months for years 3 to 5 , and every 6 months from year 6 onward. During each visit, chest and surgical site radiographs were obtained. Chest CT was performed at 6 monthly intervals or as needed. Surgical site MRI was performed every 6 months.

Treatment of disease relapse included surgical resection whenever feasible, chemotherapy, or radiotherapy.

The relapse-free interval, treatment of the relapse, postrelapse disease-free survival, and overall survival are reported. Survival analysis was performed based on the Kaplan-Meier method [8] using a commercially available statistics software program (SPSS for Windows Version 15.0, Chicago, IL, USA). 


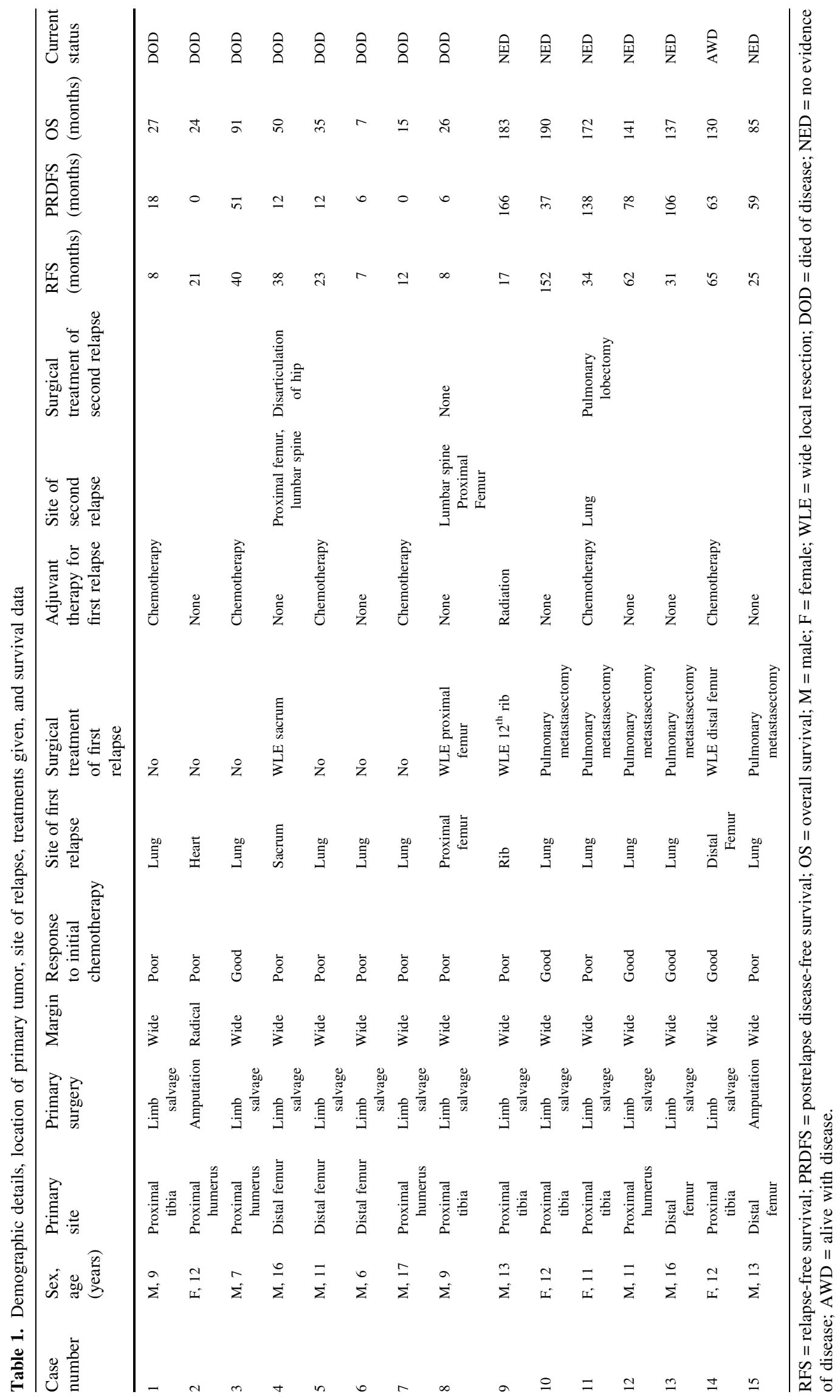




\section{Results}

In these 15 patients, disease relapsed at a median of 28 months (range, 0.7-12.6 months) from diagnosis; three had a relapse 5 years after the diagnosis of their primary lesion. Relapse was confirmed with image-guided biopsy in all cases. The most common site of relapse was the lung in 10 patients followed by bone in four patients, whereas a solitary patient developed an intracardiac lesion. Surgical resection for relapsed lesions was performed in nine patients. The surgeries included pulmonary metastasectomy in five and resection of bony lesions in four (sacrectomy, one; $12^{\text {th }}$ rib excision, one; wide local excision of femur, two) and wide margins were attained in all. Two patients in this group also received preoperative chemotherapy (one with distal femoral relapse and another with pulmonary lesions in both lungs). Another received postoperative radiation to the bed of the $12^{\text {th }}$ rib after excision (external beam radiation, $30 \mathrm{~Gy}$ in 10 fractions). Of the six patients who did not receive surgical treatment, the disease was considered too extensive for surgery. Chemotherapy was given to four patients, whereas the remaining two developed progression of disease and died without any intervention. A second relapse occurred in four patients (proximal femur in one, the lumbar spine in one, proximal femur and lumbar spine in one, and lung in one). Complete surgical clearance of the disease was possible in two of these four patients (disarticulation of the hip in one, pulmonary lobectomy in the other). In the two other patients who developed a second relapse, complete surgical clearance of the relapse could not be accomplished although the relapse in the proximal femur was cleared through a wide local resection in one and a disarticulation in the other. In both of these patients, the disease in the lumbar spine was too extensive to consider any meaningful surgical clearance. Palliative external beam radiotherapy, primarily for pain control, was given, but it did not control the disease.

In the surgically treated group, seven of the nine patients were alive at last followup with a median postrelapse disease-free survival of 78 months (range, 37-166 months) and a median overall survival of 141 months (range, 85190 months). Six of these seven patients have no evidence of disease, whereas one remains alive but was diagnosed as having a glioblastoma. She is in stable remission after surgery. Two patients died of their disease 26 and 50 months after relapse. All six patients with relapse who were not surgically treated had disease progression and died within 40 months of relapse and an overall survival ranging from 7 to 91 months. The survival curve of patients with and without surgical treatment of relapse has been depicted using the Kaplan-Meier method [8] (Fig. 1). The $95 \%$ confidence interval for median survival in the surgically

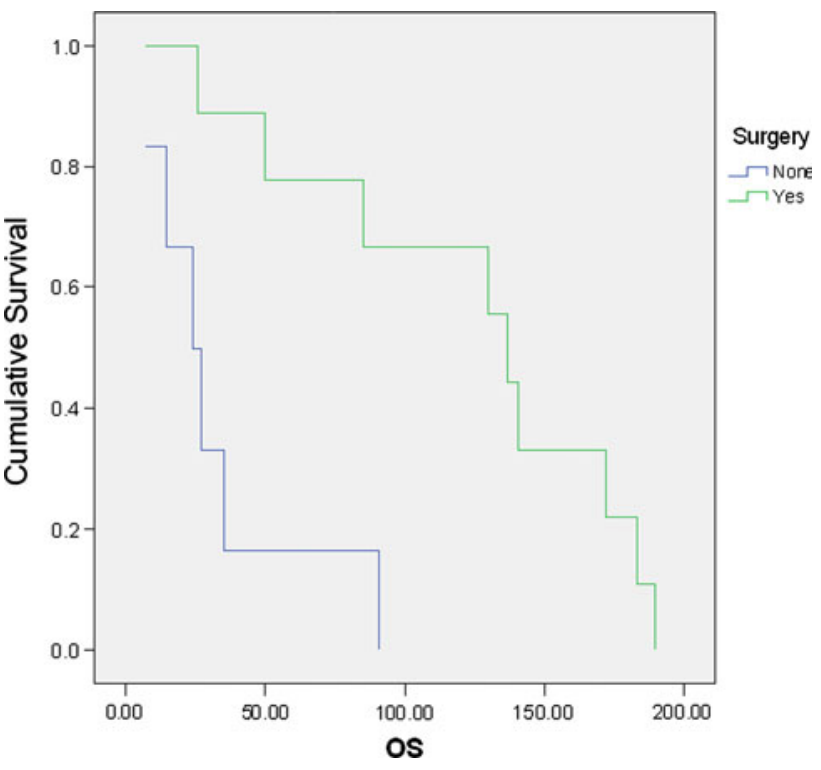

Fig. 1 Kaplan-Meier survival analysis is shown

treated group was 116 to 157 months as compared with 9 to 38 months in the nonoperated group.

The relapse-free interval (RFI) between initial diagnosis and first relapse ranged from 7 to 152 months (Table 1). The median RFI in patients who survived was 34 months (range, 17-152 months) as compared with a median of 17 months (range, 7-40 months) in patients who died after relapse.

\section{Discussion}

Relapse of osteosarcoma develops not only in patients who do not respond to systemic chemotherapy, but may also develop in patients who attain complete remission of their primary disease. Current published data [3] suggest that postrelapse survival is possible only if the patient is rendered disease-free and attains a second complete remission. Although surgical resection of the relapse seems mandatory for attaining a second complete remission, the role of chemotherapy and other adjuvant modalities of therapy is less defined. We therefore report (1) the onset, location, and treatments carried out for relapse; (2) the postrelapse disease-free survival of patients who underwent surgical ablation of their relapse and those who did not; and (3) the RFI between initial diagnosis and first relapse in survivors and in those who died of their disease.

We recognize the limitations of our study. First, ours was a retrospective analysis of a small number of patients (15) with relapse. The possible heterogeneity and potential confounding variables make statistical comparisons between the patients with and without resection impractical, yet there are noteworthy differences in subgroups that reinforce published evidence. Second, all our patients are 
in the pediatric age group (maximum age, 18 years) and have been followed up and treated by a single multidisciplinary team following a standardized protocol thereby minimizing treatment variables. Importantly, our series comprises systemic relapse, not local recurrence, which is a predictor of poor survival.

Is surgical resection required for survival? Current published evidence suggests so, and our findings concur. Ferrari et al. [5] reported on 69 (54\%) of 127 patients with osteosarcoma with localized disease who developed relapse at a median of 14 months (range, 2-96 months) after successful completion of initial treatment. Patients who had a complete resection of relapsed disease had a $30 \%$ probability of 10 -year survival. Those patients who could not be operated on because of extensive disease received chemotherapy and/or radiation, but all died within 40 months of their relapse. Patients with a relapse-free interval longer than 24 months had a 40\% 8-year survival rate compared with a $7 \%$ 8-year survival rate in those with a shorter relapse-free interval (Table 2). A followup study reported by Bacci et al. [1] echoed similar findings. Of the 235 patients with relapse, surgical clearance in 173 enabled
$52(30 \%)$ to attain complete remission and remain diseasefree at 85 months. A detailed analysis of 576 patients in the COSS [2] who developed relapse after first complete remission indicated that surgical clearance of the disease was the main factor in determining survival; $39 \%$ of 339 patients who underwent successful surgical ablation of disease were alive at 5 years. None of 229 patients in whom surgical clearance was not performed were alive at followup. A further 249 of the 576 study patients in the COSS report developed a second relapse [3]. Even in this subgroup of relapsed patients, survival was possible only through surgical ablation of disease. Five-year survival with complete surgical clearance in 119 patients was $32 \%$ for the second recurrence, $26 \%$ for the third recurrence, $28 \%$ for the fourth relapse, and $58 \%$ for the fifth relapse. None of the 130 patients without surgery attained complete remission and only three were alive at 5 years. In our study, none of the six patients who did not receive surgery attained complete remission and they all eventually died. The feasibility of surgical resection almost always determines the decision to offer surgery. We were unable to offer surgical resection for the first relapse in six patients

Table 2. Comparison of relapse intervals and postrelapse and overall survival from published studies

\begin{tabular}{|c|c|c|c|c|}
\hline \multirow[t]{2}{*}{ Author } & \multicolumn{2}{|c|}{ RFI after treatment of primary disease } & \multicolumn{2}{|l|}{$\begin{array}{l}\text { Postrelapse status } \\
\text { PRDFS or OS }\end{array}$} \\
\hline & & & $\begin{array}{l}\text { Patients undergoing surgery } \\
\text { for relapse }\end{array}$ & $\begin{array}{l}\text { Patient who were not } \\
\text { operated }\end{array}$ \\
\hline $\begin{array}{l}\text { Ferrari et al. [5] } \\
1997 \\
N=69\end{array}$ & $\begin{array}{l}<24 \text { months } \\
7 \% \\
\text { 8-year survival }\end{array}$ & $\begin{array}{l}>24 \text { months } \\
40 \% \\
\text { 8-year survival }\end{array}$ & $\begin{array}{l}\mathrm{N}=24,9 \text { attained } \mathrm{CR} \text { and } \\
\text { remained alive, } 10 \text {-year } \\
\text { probability of postrelapse } \\
\text { survival } 30 \%\end{array}$ & $\begin{array}{l}\mathrm{N}=26 \text {, none attained } \mathrm{CR}, \\
\text { all died within } 40 \text { months } \\
\text { of first relapse }\end{array}$ \\
\hline $\begin{array}{l}\text { Chou et al. [4] } \\
2005 \\
N=43\end{array}$ & $\begin{array}{l}<24 \text { months } \\
23 \% \\
\text { 3-year survival }\end{array}$ & $\begin{array}{l}>24 \text { months } \\
53 \% \\
\text { 3-year survival }\end{array}$ & $\begin{array}{l}\mathrm{N}=35,26 \text { attained second } \mathrm{CR}, \\
3 \text { died of chemotherapy } \\
\text { toxicity, } 9 \text { remained alive } \\
\text { at } 3 \text { years }\end{array}$ & $\begin{array}{l}\mathrm{N}=8 \text {, none attained } \mathrm{CR}, \\
\text { all died within }\end{array}$ \\
\hline $\begin{array}{l}\text { Bacci et al. [1] } \\
2005 \\
N=235\end{array}$ & & & $\begin{array}{l}\mathrm{N}=173,30 \% \text { attained } \mathrm{CR} \text { and } \\
\text { remain disease-free at } 85 \\
\text { months }\end{array}$ & $\begin{array}{l}\mathrm{N}=62, \text { none attained } \mathrm{CR}, \\
\text { all died at median of } \\
10 \text { months }\end{array}$ \\
\hline $\begin{array}{l}\text { Beate Kempf-Bielack } \\
\quad \text { et al. [2] } \\
2005 \\
\mathrm{~N}=568\end{array}$ & $\begin{array}{l}<18 \text { months } \\
11 \% \\
5 \text {-year survival }\end{array}$ & $\begin{array}{l}>18 \text { months } \\
34 \% \\
\text { 5-year survival }\end{array}$ & $\begin{array}{l}\mathrm{N}=339,148 \text { attained } \mathrm{CR} \text { and } \\
\text { remained alive, median } \\
\text { survival } 2.2 \text { years (range, } \\
5 \text { days to } 18.4 \text { years), } 5 \text {-year } \\
\text { overall survival } 39 \%\end{array}$ & $\begin{array}{l}\mathrm{N}=229 \text {, none attained } \mathrm{CR} \text {, } \\
\text { all died within } 44 \text { months }\end{array}$ \\
\hline $\begin{array}{l}\text { Bielack et al. [3] } \\
2009 \\
N=249\end{array}$ & & & $\begin{array}{l}\mathrm{N}=119,5 \text {-year overall } \\
\quad \text { survival } 32 \%\end{array}$ & $\begin{array}{c}\mathrm{N}=130, \text { none attained } \\
\mathrm{CR}, 5 \text {-year OS } 2 \%\end{array}$ \\
\hline $\begin{array}{l}\text { Present study } \\
\mathrm{N}=15\end{array}$ & $\begin{array}{l}\text { Nonsurvivors, median } \\
\text { RFI } 17 \text { months } \\
\text { (range, } 7-40 \text { months) }\end{array}$ & $\begin{array}{l}\text { Survivors, median } \\
\text { RFI } 34 \text { months } \\
\text { (range, 17-152 months) }\end{array}$ & $\begin{array}{l}\mathrm{N}=9,7 \text { attained } \mathrm{CR} \text { and } \\
\text { remain alive, PRDFS } \\
\text { (3-14 years), 77\% 10-year } \\
\text { postrelapse disease-free } \\
\text { survival }\end{array}$ & $\begin{array}{l}\mathrm{N}=6 \text {, all died within } \\
40 \text { months of relapse }\end{array}$ \\
\hline
\end{tabular}

$\mathrm{RFI}=$ relapse-free interval; PRDFS = postrelapse disease-free survival; OS = overall survival; $\mathrm{CR}=$ complete remission 
(either both lungs and mediastinum involved or multiple lung nodules) and for the second relapse in two patients (extensive involvement of the lumbar vertebrae). In contrast, the postrelapse disease-free survival in surgically operated patients who attained complete remission ranged from 37 to 166 months (3-14 years) and the overall survival from 85 to 190 months (7-16 years).

Does a longer RFI predict better survival? Current evidence suggests patients with late relapse have a better chance of survival than those with early relapse. Survival was better in patients with a longer RFI: RFI more than 24 months, survival 53\% at 3 years [4] and $40 \%$ at 8 years [5] compared with $23 \%$ and $7 \%$ in patients with RFI less than 24 months. In our study, the median RFI of 34 months in patients who survived was twice as long when compared with patients who died (RFI 17 months). Three of our patients developed late relapses, two with a RFI of approximately 5 years and one with a RFI of 13 years. One can only speculate whether the late relapse reflects a biologically altered disease or whether it represents a selection of a small population of chemoresistant cells that remains refractory to chemotherapy. Whether the feasibility of surgical ablation is influenced by this less aggressive variant of disease is arguable.

In conclusion, prolonged survival is possible in relapsed osteosarcoma provided the patient attains complete clinical remission after relapse. All the evidence published to date suggests that surgical ablation is the only means to attain and maintain complete remission. Neither chemotherapy nor radiation is an alternative to surgical clearance of relapse disease but both may be considered for palliative benefits. Continued disease surveillance after 5 years is necessary given that patients with possible late relapse have better survival if surgically treated. Prompt and aggressive surgical treatment of relapse must be pursued to provide postrelapse clinical remission and long-term survival.

\section{References}

1. Bacci G, Briccoli A, Longhi A, Ferrari S, Mercuri M, Faggioli F, Versari M, Picci P. Treatment and outcome of recurrent osteosarcoma: experience at Rizzoli in 235 patients initially treated with neoadjuvant chemotherapy. Acta Oncol. 2005;44:748-755.

2. Beate Kempf-Bielack B, Bielack SS, Jürgens H, Branscheid D, Berdel WE, Exner GU, Göbel U, Helmke K, Jundt G, Kabisch H, Kevric M, Klingebiel T, Kotz R, Maas R, Schwarz R, Semik M, Treuner J, Zoubek A, Winkler K. (2005) Osteosarcoma relapse after combined modality therapy: an analysis of unselected patients in the Cooperative Osteosarcoma Study Group (COSS). J Clin Oncol 23:559-568.

3. Bielack SS, Kempf-Bielack B, Branscheid D, Carrle D, Friedel G, Helmke K, Kevric M, Jundt G, Kühne T, Maas R, Schwarz R, Zoubek A, Jürgens H. Second and subsequent recurrences of osteosarcoma: presentation, treatment, and outcomes of 249 consecutive Cooperative Osteosarcoma Study Group patients. J Clin Oncol. 2009;27:557-565.

4. Chou AJ, Merola PR, Wexler LH, Gorlick RG, Vyas YM, Healey $\mathrm{JH}$, LaQuaglia MP, Huvos AG, Meyers PA. Treatment of osteosarcoma at first recurrence after contemporary therapy. Cancer. 2005;104:2214-2221.

5. Ferrari S, Bacci G, Picci P, Mercuri M, Briccoli A, Pinto D, Gasbarrini A, Tienghi A, Brach del Prever A. Long term follow up and post relapse survival in patients with non-metastatic osteosarcoma of the extremity treated with neoadjuvant chemotherapy. Ann Oncol. 1997;8:765-771.

6. Huvos AG, Rosen G, Marcove RC. Primary osteogenic sarcoma: pathologic aspects in 20 patients after treatment with chemotherapy en bloc resection, and prosthetic bone replacement. Arch Pathol Lab Med. 1977;101:14-18.

7. Jaffe N. Osteosarcoma: review of the past, impact on the future. The American experience. Cancer Treat Res. 2009;152:239-262.

8. Kaplan EL, Meier P. Nonparametric estimation from incomplete observations. J. Am. Stati. Assn. 1958;53:457-481.

9. Ritter J, Bielack SS. Osteosarcoma. Ann Oncol. 2010;21(Suppl 7): vii, 320-325. 